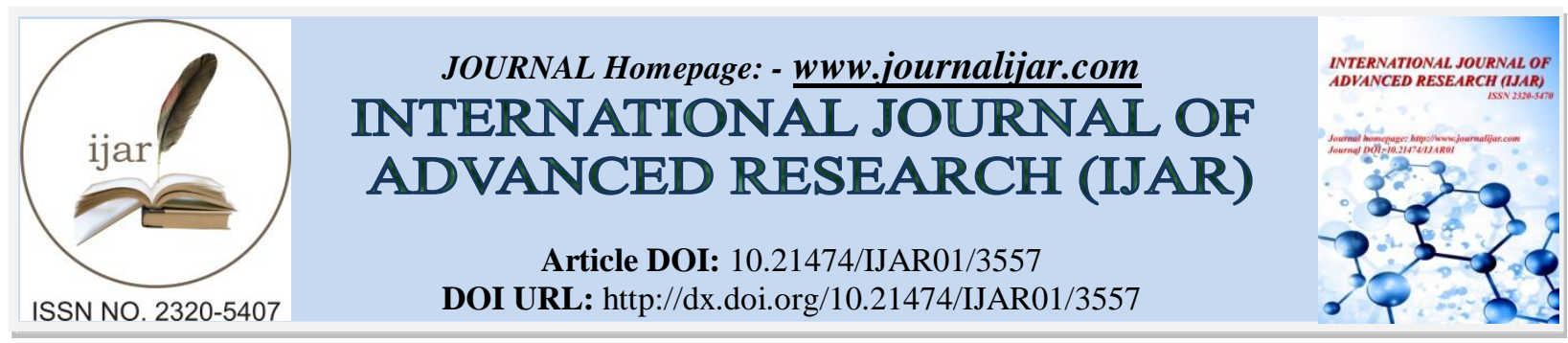

RESEARCH ARTICLE

\title{
PREVALENCE OF OVERWEIGHT AND OBESITY AMONG RURAL PRESCHOOL SCHOOL CHILDREN CAMEROON.
}

"Damaris Enyegue Mandob, Nguimbus Oum Madeleine Estelle and Bikono Samba Ange Gallus Fridolin. Department of Biological Sciences, Higher Teachers' Training College, University of Yaoundé I, P.O. Box 047, Yaoundé, Cameroon.

\section{Manuscript Info}

Manuscript History

Received: 02 January 2017

Final Accepted: 05 February 2017

Published: March 2017

Key words:-

Obesity, Prevalence, Preschool children, rural Cameroon.

\section{Abstract}

Background: Pediatric obesity is becoming a public health issue across several countries. Childhood obesity has immediate and longterm impacts on physical, social, and emotional health.Limited data concerning obesity among preschool children are available in rural Cameroon.

Aim: The aim of this study was to determine the prevalence and risk factors associated with overweight and obesity among rural nursery school children in Ngog-Mapubi Cameroon.

Material and Methods: This was a cross sectional study conducted in nursery school childrenaged between 2-5 years during the month of March 2016 at the public rural nursery school of Ngog-Mapubi Cameroon. Obesity and overweight were defined according WHO. Data were analyzed using Stata version 11. The Chi- square test was used to assess the association between respondent characteristics and the prevalence of overweight and obesity. Logistic regression was used for determination of risk factors of childhood overweight and obesity.

Results: Out of total 100 children recruited in this study, The overall prevalence of overweight is $40 \%$ (55.10\% for boys and $25.49 \%$ for girls) while the overall prevalence of obesity is $13 \%(8.16 \%$ for boys and $17.64 \%$ for girls).

Conclusion: Finally, the cumulative prevalence of obesity is $53 \%$ in the studied population. Parent rentals and Child watches television after school were significantly associated to overweight while Parent rentals and Child eats snacks were significant predictor of obesity.

Copy Right, IJAR, 2017,. All rights reserved.

\section{Introduction:-}

Overweight and obesity among preschool children is becoming an emerging public health issue. It recognized that all their life, childhood obesity is associated with immediate and long-term impacts on psychological, physical, social, and emotional health troubles. Children with obesity are at higher risk for having other chronic health such as asthma, sleep apnea, bone and joint problems, type 2 diabetes, and risk factors for heart disease and diseases that impact physical health, [1, 2,3-5]. Children with obesity are bullied and teased more than their normal weight peers, [6] and are more likely to suffer from social isolation, depression, and lower self-esteem. ${ }^{[7}$ In the long term, childhood obesity also is associated with having obesity as an adult, ${ }^{[8]}$ which is linked to serious conditions and diseases such

Corresponding Author:- DAMARIS Enyegue Mandob.

Address:- Department of Biological Sciences, Higher Teachers' Training College, University of Yaoundé 673 I, P.O. Box 047, Yaoundé, Cameroon. 
as heart disease, type 2 diabetes, metabolic syndrome, and several types of cancer. ${ }^{[9-10]}$ In developed countries, many reports, have shown increasing numbers of overweight children ${ }_{[11-13]}$. Developing countries are facing the double burden of under nutrition over nutrition and the extent of the problem remains unknown. Projections show that prevalence among children of less than 5 years) obesity will attend the magnitude of $12.7 \%$ in Africa by $2020_{\text {[14] }}$ In Cameroon, scarce childhood obesity data are available ${ }_{[15]}$. This study was carried out to estimate the prevalence of overweight and obesity among rural preschool children of 2 to 5 years

\section{Materials and Methods:-}

\section{Ethics:-}

The study was conducted during the month of March 2016 at the public rural nursery school of Ngomapubi Cameroon. Admission to the study was based solely on voluntary authorization of the parents or the guardians who provided their verbal informed consent. The study was approved by the Education Planning Commission of the hospital of Ngog mapubi.

\section{Subjects:-}

Our cross sectional study was carried out on 100 healthy preschool aged children the aged between 2 and 5 years. Data were collected during the month of March 2016 by applying a standard questionnaire to the mothers, the fathers or guardians. The parents filled the questionnaire regarding age, sex, education and occupation of the parent, family size, family history of chronic diseases, eating habits of junked food.

For each child anthropometric measurement of weight, Height, health examination and blood pressure measurement. Height and weight measurements were taken for each subject using adequate methodology of Weiner and Lourie 1981 et al[16]. The height was measured in standing position using tape meter while the shoulder was in a normal position to the nearest. Body weight were determined in participants (with very light clothing on and without shoes) using a Jocca ${ }^{\mathrm{TM}}$ scale.

The blood pressure was measured by one nurse with Labell TM electronic blood pressure on the wrist. If one child was crying, the blood pressure was not taken until he or she became calm. The determined systolic and diastolic pressures were ascertained from three readings using the mean value of the three. Blood pressure was measured 3 times on the left arm and in the sitting position, with at least $10 \mathrm{~min}$ of rest before the first measurement and a twominute interval between measurements, according standardized techniques.

\section{Definition of Overweight and Obesity:-}

Body mass index (BMI) was calculated as weight in kilograms divided by square of height in metres. International criteria for BMI percentiles for age and sex (Cole et al. $2000_{[17]}$. BMI is a measure used to determine childhood overweight and obesity. Overweight is defined as a BMI at or above the $85^{\text {th }}$ percentile and below the $95^{\text {th }}$ percentile for children and teens of the same age and sex. Obesity is defined as a BMI at or above the 95th percentile for children and teens of the same age and sex.

\section{Statistical Analysis:-}

The survey sample was categorized according to age and gender, All data were analyzed by STATA version 13 . The data were classified into four age groups, each of one-year

duration, i.e., age group 2+ included children from age 2.00-2.99 years, the age group 3+ from 3.00-3.99 years and so on. Categorical variables are presented as percentages or numbers. The chi-square test respectively, $\mathrm{P}$ value $<0.05$ was considered statistically significant.

Logistic regression was performed with adjustment for all variables for identification of risk factors for overweight and obesity

\section{Results:-}

Of the 100 children, were (49\%) were males and 51\% females. Their age ranged from $2-5$ years. Table 1 shows the distribution of the studied population according to age. Most of the girl assessed had 4 years while the majority of the boys had five years. Table 2 reports the prevalence of overweight among boys and girls, the highest prevalence of overweight was reported among boys of 5years while the lowest was noted among girls of 5years. They were a significant difference among overweight prevalence of boys and girls of 5years. 
Table 3 reports the prevalence of obesity among boys and girls, the highest prevalence of obesity was reported among girls of 3years while the lowest was noted among girls of 5years and boys $\mathrm{f} 3$ years. They were a significant difference among obesity prevalence of boys and girls of 3 years.

Table 4 show factors associated with overweight. Parent rentals and Child watches television after school were significantly associated to overweight.

Table 5 show factors associated with obesity. Parent rentals and Child eats snacks were significant predictor of obesity.

According to table 4 and 5, boys exhibit higher significant prevalence of overweight but lower prevalence of obesity comparatively to girls. The overall prevalence of overweight is $40 \%$ (55.10\% for boys and $25.49 \%$ for girls) while the overall prevalence of obesity is $13 \%$ (8.16\% for boys and $17.64 \%$ for girls). Finally, the cumulative prevalence of obesity is $53 \%$ in the studied population.

Table 1:- Characteristics of nursery school children

\begin{tabular}{|c|c|c|c|}
\hline Age(years) & $\operatorname{Boys}\left({ }^{\circ} / \circ\right)$ & $\operatorname{Girls}\left({ }^{\circ} / \circ\right)$ & Total $\left({ }^{\circ} / \circ\right)$ \\
\hline $2+$ & $7(33.33)$ & $14(66.67)$ & 21 \\
\hline $3+$ & 11(40.74) & $16(59.26)$ & 27 \\
\hline $4+$ & $10(37.07)$ & $17(62.96)$ & 27 \\
\hline $5+$ & $21(84.00)$ & $4(16.00)$ & 25 \\
\hline $2+3+4+5+$ & $49(49.00)$ & $51(51.00)$ & 100 \\
\hline
\end{tabular}

Table 2:- Prevalence of overweight among boys and girls

\begin{tabular}{|l|l|c|c|}
\hline Age(years) & $\operatorname{Boys}^{\circ}\left({ }^{\circ}\right)$ & $\left.\operatorname{Girls}^{\circ} \stackrel{\circ}{\circ}\right)^{*}$ & P value \\
\hline $\mathbf{2 +}$ & 28.57 & 21.42 & 0.717 \\
\hline $\mathbf{3 +}$ & 27.27 & 31.25 & 0.840 \\
\hline $\mathbf{4 +}$ & 10.00 & 29.41 & 0.241 \\
\hline $\mathbf{5 +}$ & 100 & 0.00 & $0.000^{*}$ \\
\hline $\mathbf{2 + 3 + 4 + 5 +}$ & 55.10 & 25.49 & $0.029^{*}$ \\
\hline
\end{tabular}

Table 3:- P revalence of obesity among boys and girls

\begin{tabular}{|c|c|c|c|}
\hline Age(years) & $\operatorname{Boys}\left({ }^{\circ} / \circ\right)$ & $\operatorname{Girls}\left({ }^{\circ} /{ }^{\circ}\right)$ & $P$ value \\
\hline $2+$ & 14.28 & 7.14 & 0.599 \\
\hline $3+$ & 0.00 & 43.75 & $0.011 *$ \\
\hline $4+$ & 10.00 & 5.88 & 0.693 \\
\hline $5+$ & 14.28 & 0.00 & 0.420 \\
\hline $2+3+4+5+$ & 8.16 & 17.64 & $0.034 *$ \\
\hline
\end{tabular}

Table 4:- Risk factors for overweight among nursery school

\begin{tabular}{|l|l|}
\hline Variables & Odd ratio $(\mathbf{9 5 \%} \mathbf{C I})$ \\
\hline Parent rentals & $1.26(0.55-2.99)^{*}$ \\
\hline Parent Fatnesss & $0.71(0.23-2.21)$ \\
\hline Child watches television after school & $1.55(0.60-4.00)^{*}$ \\
\hline Full meal from appetizer to dessert & $0.84(0.36-1.96)$ \\
\hline Child eats snacks regularly & $0.84(0.34-2.06)$ \\
\hline
\end{tabular}

$* P<0.05$ considered significant 
Table 5:- Risk factors Obesity for among nursery school

\begin{tabular}{|l|l|}
\hline Variables & Odd ratio (95\% CI) \\
\hline Parent rentals & $1.77(0.53-5.86)^{*}$ \\
\hline Parent Fatnesss & $0.68(0.12-3.65)$ \\
\hline Child watches television after school & $1.30(0.35-4.87)$ \\
\hline Full meal from appetizer to dessert & $0.60(0.18-2.04)$ \\
\hline Child eats snacks regularly & $1.64(0.49-5.48)^{*}$ \\
\hline
\end{tabular}

\section{Discussion:-}

Childhood obesity is becoming a worldwide serious public health problem. Obesity in childhood is tend to be maintained in adulthood with series of unhealthy events such as dyslipideamia, hypertension, type 2 diabetes, metabolic syndrome and psychosocial disorders. Obesity has reached pandemic proportion in Cameroon and to limit that pandemic, prevention of adult obesity induced morbidity and mortality should be trigger as early as possible in childhood. Scarce studies have been conducted on overweight and obesity prevalence and risk factors among preschool children in rural areas of Cameroon. This study was carried out to estimate the prevalence of overweight and obesity among rural preschool children aged between 2 and 5years old of Ngog Mapubi nursery school and to contribute to find effective ways to prevent childhood obesity.

The prevalence of overweight and obesity in our study is too high and does not favour comparison with others studies. This prevalence was higher than the previous Cameroonian (8.0\%) study[15] and others sub-Saharan African studies done in Ivory Coast (4.4\% in 2012), in Nigeria (6.3\% in 2013), in Senegal (6.8\% in 2013), and Democratic Republic of Congo (5.6\% in 2014) [18]. Many reason can justified this great prevalence, the small sample size, the definition used, the age of participants and the socio-economic status.

In our study, prevalence of obesity varies with gender difference, it was noted that boys were more at risk of overweight while girls were more obese. This finding is consistent with many studies [19,20,21], but in contrast with reports with girl obesity predominance[22-26] and no gender difference noticed among boys and girls [27,28].

It is well known that overweight is a result of interactions between genetic and environmental factors, metabolism, eating and physical activity behaviour, and social and individual psychology[29-32] It has been found that parent rental is a risk factor of obesity, infact our study area is a rural area where only civil servant with high incomes are transferred for professional reasons and are obliged to rent houses because they are not in their native village. This is supported by the reports show that in developing countries, a positive association is noted has between obesity and children of high parents having a high socioeconomic status, [33].

Inactivity through watching television after school and eating snacks regularly are obesity risk factors in our study. Television influence the dietary behaviors of children and reduces their daily physical activity level and consuming more energy from snack with added sugars or solid fats than the body uses for healthy functioning, growth, and physical activity, leads to obesity. [34,35,36].

This study has some major limitations, the small sample size of population recruited only in Ngog Mapubi and it cross-sectional nature prevents it to be generalized in all rural preschool children.

\section{Conclusion:-}

These findings brings out the reality of child obesity among preschoolers in rural Cameroon and support the need for practical actions to be taken at the level of schools, parents and children to bar the way to obesity epidemic.

\section{Acknowledgements:-}

The author thank all the children who participated, their parents, teachers and the Head of the the nursery schools for their support their parents as well as the hospital personnel for the collection of the data.

\section{Declaration of Conflicting Interest:-}

The authors declare that there are no conflicts of interest.

\section{Funding:-}

This research received no specific grant from any funding agency in the public, commercial, or not for profit sectors. 


\section{References:-}

1. Institute of Medicine, Accelerating progress in obesity prevention: solving the weight of the nation. 2012, Washington, DC: National Academies Press.

2. US Department of Health and Human Services. The Surgeon General's Vision for a Healthy and Fit Nation. Rockville, MD: US Dept., Health and Human Services; 2010.

3. Must A, Hollander SA, Economos CD, Childhood obesity: a growing public health concern. Expert Review of Endocrinology \& Metabolism, 2006. 1(2): p. 233-254.

4. Freedman DS, Dietz WH, Srinivasan SR, Berenson GS, Cardiovascular risk factors and excess adiposity among overweight children and adolescents: the Bogalusa Heart Study. The Journal of pediatrics, 2007. 150(1): p. 1217. e2.

5. May AL, Kuklina EV, Yoon PW, Prevalence of Cardiovascular Disease Risk Factors Among US Adolescents, 1999-2008. Pediatrics, 2012. 129(6): p. 1035-1041.

6. van Geel M, Vedder P, Tanilon J, Are overweight and obese youths more often bullied by their peers? A metaanalysis on the correlation between weight status and bullying. Int J Obes (Lond), 2014. 38(10): p. 1263

7. Ogden CL, Carroll MD, Lawman HG, Fryar CD, Kruszon-Moran D, Kit BK, Flegal KM, Trends in Obesity Prevalence Among Children and Adolescents in the United States, 1988-1994 Through 2013-2014. JAMA, 2016. 315(21): p. 2292-2299.

8. National Heart Lung and Blood Institute. Aim for a Healthy Weight. [cited 2016 August 24]; Available from: http://www.nhlbi.nih.gov/health/educational/lose_wt/.

9. White House Task Force on Childhood Obesity, Solving the problem of childhood obesity within a generation. White House Task Force on Childhood Obesity Report to the President. 2010: Washington, DC.

10. Hoelscher DM, Kirk S, Ritchie L, Cunningham-Sabo L, et al., Position of the Academy of Nutrition and Dietetics: interventions for the prevention and treatment of pediatric overweight and obesity. Journal of the Academy of Nutrition and Dietetics, 2013. 113(10): p. 1375-1394.

11. Ogden CL, Troiano RP, Briefel RR, Kuczmarski RJ, Flegal KM, Johnson CL. Prevalence of overweight among preschool children in the United States, 1971 through 1994. Pediatrics [serialonline] 1997;99:E1. World Wide Web: http://www.pediatrics.org/cgi/content/full/99/4/e1 (accessed 1 August 2000).

12. Shirai K, Shinomiya M, Saito Y, Umezono T, Takahashi K, YoshidaS. Incidence of childhood obesity over the last 10 years in Japan.Diabetes Res Clin Pract 1990;10(suppl):S65-70.

13. Hardcastle DM, Shrimpton S, Renigeris AS, Baptist ED, Baur LA. Increasing prevalence of childhood obesity. Med J Aust 1997;167:342

14. de Onis M, Blossner M, Borghi E. Global prevalence and trends of overweight and obesity among preschool children. Am J Clin Nutr. 2010 Sep 22; 92(5):1257-64. doi: 10.3945/ajcn.2010.29786 PMID:20861173.

15. Tchoubi S, Sobngwi-Tambekou J, NoubiapJJN, Asangbeh SL, Nkoum BA, Sobngwi E (2015)Prevalence and Risk Factors of Overweight and Obesity among Children Aged 6-59 Months in Cameroon: A Multistage, Stratified Cluster Sampling Nationwide Survey. PLoS ONE e0143215.doi:10.1371/journal.pone.0143215

16. Weiner JS, Lourie JA 1981. Practical Human Biology.New York: Academic Press.

17. Cole TJ, Bellizzi MC, Flegal KM, Dietz WH 2000. Establishing a standard definition for childoverweight and obesity worldwide: International survey. Br Med J, 320: 1240-1243.

18. WHO. Global Database on child Growth and Malnutrition/Countries and territories [Internet].WHO.[Accessed 3 May 2015]. Available: http://www.who.int/nutgrowthdb/database/countries/en

19. Dubois L, Girard M. Early determinants of overweight at 4.5 years in a population-based longitudinalstudy. Int J Obes. 2006 Apr; 30(4):610-7.

20. .Jouret B, Ahluwalia N, Cristini C, Dupuy M, Nègre-Pages L, Grandjean H, et al. Factors associated with overweight in preschool-age children in southwestern France. Am J Clin Nutr. 2007 Jun 1; 85(6):1643-9. PMID: 17556704

21. Fatemeh T, Mohammad-Mehdi H- T, Toba K, Afsaneh N, Sharifzadeh G, and Student Research committee. Prevalence of overweight and obesity in preschool children (2-5 year-olds) in Birjand, Iran.BMC Res Notes. 2012; 5(1):529.

22. Reilly JJ, Armstrong J, Dorosty AR, Emmett PM, Ness A, Rogers I, et al. Early life risk factors for obesityin childhood: cohort study. BMJ. 2005 Jun 9; 330(7504):1357. PMID: 15908441

23. Kitsantas P, Gaffney KF. Risk profiles for overweight/obesity among preschoolers. Early Hum Dev.2010 Sep; 86(9):563-8. doi: 10.1016/j.earlhumdev.2010.07.006 PMID: 20716472 
24. Kuhle S, Allen AC, Veugelers PJ. Perinatal and childhood risk factors for overweight in a provincialsample of Canadian Grade 5 students. Int J Pediatr Obes. 2010 Jan; 5(1):88-96. doi: 10.3109/17477160903060028 PMID: 19565401

25. Kramoh KE, N'goran YNK, Aké-Traboulsi E, Boka BC, Harding DE, Koffi DBJ, et al. Prévalence del'obésité en milieu scolaire en Côte d'Ivoire. Ann Cardiol Angéiologie. 2012 Jun; 61(3):145-9.

26. Rooney BL, Mathiason MA, Schauberger CW. Predictors of Obesity in Childhood, Adolescence, and Adulthood in a Birth Cohort. Matern Child Health J. 2010 Oct 7; 15(8):1166-75.

27. Moraeus L, Lissner L, Yngve A, Poortvliet E, Al-Ansari U, Sjöberg A. Multi-level influences on childhood obesity in Sweden: societal factors, parental determinants and child's lifestyle. Int J Obes. 2012 May 22 ; 36(7):969-76.

28. Tabacchi G, Giammanco S, La Guardia M, Giammanco M. A review of the literature and a new classification of the early determinants of childhood obesity: from pregnancy to the first years of life. Nutr Res.2007 Oct; 27(10):587-604.

29. Institute of Medicine, Accelerating progress in obesity prevention: solving the weight of the nation. 2012, Washington, DC: National Academies Press.

30. US Department of Health and Human Services. The Surgeon General's Vision for a Healthy and Fit Nation. Rockville, MD: US Dept., Health and Human Services; 2010.

31. Finegood DT, Merth TDN, Rutter H, Implications of the Foresight Obesity System Map for Solutions to Childhood Obesity. Obesity, 2010. 18(S1): p. S13-S16.

32. Gupta N, Goel K, Shah P, Misra A. Childhood Obesity in Developing Countries: Epidemiology, Determinants, and Prevention. Endocr Rev. 2012 Jan 12; 33(1):48-70. doi: 10.1210/er.2010-0028 PMID:22240243

33. Hill JO, Wyatt HR, Peters JC., Energy balance and obesity. Circulation, 2012. 126(1): p. 126-132.

34. U.S. Department of Agriculture and U.S. Department of Health and Human Services, Dietary Guidelines for Americans, 2015-2020. 2015, U.S. Government Printing Office: Washington, DC.

35. 36.Vandenbroeck P, Goossens J, and Clemens M, Foresight, Foresight, tackling obesities: future choicesbuilding the obesity system map. London: Government Office for Science, 2007. 